\title{
Germicidal Activities of Representatives of Five Different Teat Dip Classes Against Three Bovine Mycoplasma Species Using a Modified Excised Teat Model
}

\author{
R. L. Boddie, W. E. Owens, C. H. Ray, S. C. Nickerson, and N. T. Boddie \\ Mastitis Research Laboratory, Hill Farm Research Station, \\ Louisiana Agricultural Experiment Station, \\ Louisiana State University Agricultural Center, \\ Homer 71040
}

\begin{abstract}
Six representative teat dips from five different teat dip classes were tested for germicidal activity against challenge exposure to Mycoplasma bovis, Mycoplasma californicum, and Mycoplasma bovigenitalium using a modified excised teat model. All teat dip formulations tested were efficacious against all of the Mycoplasma species, providing bacterial logarithmic reductions above 4 . The germicides performed best against $M$. bovigenitalium with an average log reduction (LR) of 6.29. Average LR were 5.41 and 5.70 against $M$. bovis and $M$. californicum, respectively. The iodine and chlorhexidine products performed best against $M$. bovis and $M$. californicum, respectively, with complete kill of all organisms. The chlorhexidine and the barrier chlorine product also had complete kill of $M$. bovigenitalium organisms.
\end{abstract}

(Key words: teat dip, Mycoplasma spp., excised teat model)

Abbreviation key: $\mathbf{L R}=\log$ reduction.

\section{INTRODUCTION}

Mastitis caused by Mycoplasma species is becoming recognized more frequently as veterinarians and laboratory personnel become familiar with the clinical symptoms of the disease and the culture technique needed to identify infections. Mycoplasma species are found as normal flora of cattle nasal mucous membranes, respiratory surfaces, and the urogenital tract, as well as on teat skin. Due to the severity of clinical mycoplasmal mastitis, the lack of approved antimicrobial therapy, and because the organism is found in an opportune site on teat skin for development of IMI;

Received January 18, 2002.

Accepted March 20, 2002.

Corresponding author: W. E. Owens; e-mail: wowens@ agctr.lsu.edu. proper udder hygiene is very important for reducing numbers of Mycoplasma species on teat skin (Laboratory Handbook, 1999). During mycoplasmal mastitis outbreaks it has been recommended that sanitary practices be upgraded to include segregation of infected cows, teat dipping, and dipping milking clusters in a sanitizer between cows (Jasper et al., 1976). In the past, the effectiveness of various teat dips against mycoplasmas was not considered relevant. Not until Jasper et al. (1976) tested seven teat dip and sanitizer products against $M$. bovis was there any research showing teat dip efficacy against Mycoplasma species. This study revealed that the chlorine, iodine, and chlorhexidine teat dips tested were very effective against $M$. bovis on teat skin. Since that initial research more than $25 \mathrm{yr}$ ago, many new teat dips have been developed that have not been tested against $M$. bovis, the most common bovine mycoplasmal mastitis pathogen, or any of the other Mycoplasma species causing mastitis. The objective of this study was to evaluate teat dips representing different teat dip classes against the three most common bovine mycoplasmal mastitis pathogens using a modified excised teat model (Philpot et al., 1978).

\section{MATERIALS AND METHODS}

Descriptions of the teat dips tested are found in Table 1. Teats that were used during each trial were collected from slaughtered dairy cows. Excess skin and tissue was trimmed, teats were washed in a mild detergent and warm water, rinsed in water, dried, and dipped in $70 \%$ ethyl alcohol. Teats were discarded that had rough skin, chaps, or abrasions. Teats were placed in plastic bags in a glycerin and water solution and frozen at $-20^{\circ} \mathrm{C}$ until further use. The mycoplasmal strains used for each trial were Mycoplasma bovis American Type Culture Collection 25523; Mycoplasma californicum Willet 9978 received from R. N. Gonzalez, QMPS, College of Veterinary Medicine, Cornell University, Ithaca, NY, and Mycoplasma bovigenitalium, received from J. S. Cullor, University of California, Davis. 


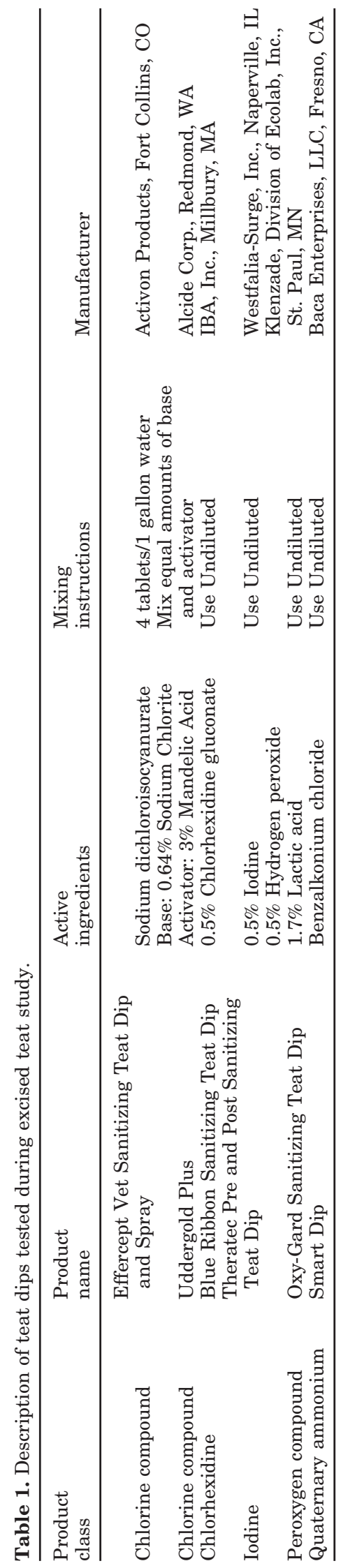

For preparation of the challenge inoculum of each Mycoplasma species, six 10-ml tubes of mycoplasma broth (Becton Dickinson, Cockeysville, MD), to which enrichment supplements of 20\% inactivated horse serum (Sigma Chemical Co., St. Louis, MO) and 2.5\% yeast extract (Becton Dickinson) were added, were inoculated heavily with colonies actively growing on mycoplasmal agar (Becton Dickinson). The mycoplasmal agar was supplemented with $10 \%$ inactivated horse serum, $1 \%$ yeast extract, $0.05 \%$ thallium acetate (Sigma Chemical Co.), $0.002 \%$ DNA (Sigma Chemical Co.), and $1000 \mathrm{units} / \mathrm{ml}$ of penicillin (Sigma Chemical Co.). The inoculum was incubated at $37^{\circ} \mathrm{C}$ in $10 \% \mathrm{CO}_{2}$ atmosphere for $72 \mathrm{~h}$. The optical density of the inoculum was determined using a 20 Genesys spectrophotometer (Spectronic Unicam, Rochester, NY) and the organism population was adjusted to approximately $1 \times 10^{8} \mathrm{cfu} /$ $\mathrm{ml}$ of each organism by use of a standard curve made by data obtained from previous serial dilutions and standard plate counts. Serial dilutions of the challenge inoculum were made before each trial began, and a standard plate count conducted on mycoplasmal agar. The teat dip quenching solution was letheen broth (Becton Dickinson) modified to contain $1 \%$ sodium thiosulfate (Sigma Chemical Co.).

Each trial used 10 teats for testing the products as well as the negative control. Frozen teats were thawed in warm water, dipped in $70 \%$ ethyl alcohol, dried with a paper towel, and suspended by metal clips from a glass rod. Teats were dipped in the challenge suspension once to a depth of approximately $15 \mathrm{~mm}$ and allowed to drain for $5 \mathrm{~min}$, then dipped with the test product to a depth of approximately $30 \mathrm{~mm}$ and drained for an additional $10 \mathrm{~min}$. For undipped negative control teats, the drainage time was $15 \mathrm{~min}$.

Organisms were removed by rinsing each teat with approximately $5 \mathrm{ml}$ of quencher expressed from a polyethylene wash bottle. The quencher was maintained at $5^{\circ} \mathrm{C}$ during each trial. The $5-\mathrm{ml}$ rinse was collected in sterile blood cell-counter vials (VWR Scientific Products, Atlanta, GA). Plating of the rinse was in 0.1-ml amounts on mycoplasmal agar. Rinses from negative control teats required plating at $10^{-4}$ to achieve countable plates, while rinses from teats dipped with the test products were not diluted before plating. Plates were incubated for $7 \mathrm{~d}$ at $37^{\circ} \mathrm{C}$ in $10 \% \mathrm{CO}_{2}$ atmosphere, and colonies were counted using a stereo microscope at $3 \times$ magnification. The geometric mean of colonies counted was determined, multiplied by 50 to express the total volume of rinse, and then multiplied by the dilution factor to yield the total colony-forming units recovered from the rinse of each teat. The total colony-forming units recovered for each product tested was converted to $\log$ form, and this log value was subtracted from 
Table 2. Germicidal activity of various teat dips against Mycoplasma species.

\begin{tabular}{lllll}
\hline & & $\begin{array}{l}\text { M. bovis } \\
\text { Pog reduction } \\
\text { from control }\end{array}$ & $\begin{array}{l}\text { M. californicum } \\
\text { Log reduction } \\
\text { from control }\end{array}$ & $\begin{array}{l}\text { M. bovigenitalium } \\
\text { Log reduction } \\
\text { from control }\end{array}$ \\
\hline Effercept $^{1}$ & Germicide & Sodium dichloroisocyanurate & 4.79 & 5.84 \\
Uddergold $^{2}$ Plus & 0.64\% Sodium chlorite 3\% Mandelic acid & 5.96 & 5.73 & 6.27 \\
Blue Ribbon $^{3}$ & 0.5\% Chlorhexidine gluconate & 5.15 & - & - \\
Theratec $^{4}$ & 0.5\% Iodine & -7 & 6.68 & 6.42 \\
Oxy-Gard $^{5}$ & 0.5\% Hydrogen peroxide 1.7\% Lactic acid & 4.60 & 4.38 & 6.00 \\
Smart Dip $^{6}$ & Benzalkonium chloride & 6.56 & 5.88 & 6.49 \\
\hline
\end{tabular}

${ }^{1}$ Action Products, Fort Collins, CO.

${ }^{2}$ Alcide Corp., Redmond, WA.

${ }^{3}$ IBA, Inc., Millbury, MA.

${ }^{4}$ Westfalia Surge, Inc., Naperville, IL.

${ }^{5}$ Klenzade, Division of Ecobb, Inc., St. Paul, MN.

${ }^{6}$ Boca Enterprises, LLC, Fresno, CA.

${ }^{7}$ Complete kill of all microorganisms by the teat dip.

the log value for the negative control to yield the log reduction (LR) for that product. In cases where organisms were not recovered from a teat, the value of 0.01 was substituted for zero in determining mean counts.

The same set of teats was used for each run within a trial. Between runs, teats were rinsed in warm water for $2 \mathrm{~min}$ with agitation, dried, rinsed in a $0.05 \%$ sodium thiosulfate solution (Sigma Chemical Co.) for $1 \mathrm{~min}$, dried, rinsed in a solution containing $0.05 \%$ lecithin (Fisher Scientific, Fair Lawn, NJ) and 0.05\% Tween 80 (Fisher Scientific) for $1 \mathrm{~min}$, dried, rinsed in warm water for $1 \mathrm{~min}$, dried, dipped in 70\% ethyl alcohol, dried, and resuspended on the glass rod to air dry before commencement of the next run.

\section{RESULTS}

An effective teat dip should achieve a 3 and preferably, a 4 or 5 LR of microorganisms using an excised teat model (Philpot et al., 1978). Data for the teat dips tested are presented in Table 2. All of the teat dips tested were efficacious against all of the Mycoplasma species, providing LR above 4 . The germicides performed best against $M$. bovigenitalium with an average LR of 6.29. Average LR were 5.41 and 5.70 against $M$. bovis and $M$. californicum, respectively. It should be noted that the active ingredients in Effercept Vet Sanitizing Teat Dip (sodium dichloroisocyanurate) and Uddergold Plus (sodium chlorite and mandelic acid) are different, although both are classified as chlorine compounds. Both teat dips kill microorganisms by chlorination and oxidation of the cell and internal proteins, including enzymes (Boddie et al., 1994; Boddie and Nickerson, 1996).

Mycoplasmal microorganisms may seem to be fragile and easy to destroy under laboratory conditions; however, in the field they may be more resistant to teat dips because of their protection in milk and other organic materials (Bushnell, 1984). The ability of the tested strains to survive on the negative control teats in this assay for 15 min indicates that these organisms can survive on teat surfaces long enough to be transmitted from cow to cow. Mycoplasma bovis was the most resistant to germicides of the common mastitis-causing species in this study. In a study of neutralization of germicidal activity of disinfectants by OM, a $2 \%$ iodophor and a chlorine product showed a low tolerance of OM, including whole milk powder. A $1.6 \%$ chlorhexidine acetate and an anionic acid were only moderately affected by the presence of OM (Gelinas and Goulet, 1983). $M y$ coplasma can be introduced into a herd in ways other than mycoplasmal mastitis. Cows or calves with Mycoplasma pneumonia spread the disease to other herdmates and provide a reservoir of infection that could lead to mycoplasmal IMI (Bushnell, 1984). Teat dip use is only one tool to help eliminate Mycoplasma on teat skin. Cows and heifers purchased should be screened for mycoplasmal IMI and respiratory disease before entering the herd. Proper udder infusion procedures and sanitization of milk equipment will also reduce the spread of mycoplasmal IMI.

The spread of mycoplasmal mastitis does continue in herds that practice teat dipping, but teat dip use can still be a good procedure for reducing the numbers of Mycoplasma on teat skin, therefore reducing the rate of spread of mycoplasmal IMI.

\section{CONCLUSIONS}

Mastitis caused by Mycoplasma species is being recognized more frequently than in the past. Mycoplasma species are commonly found on nasal mucous membranes, respiratory and urogenital surfaces, and teat skin. Udder infections are spread from cow to cow by 
physical contact and are precipitated by breakdowns in sanitation, equipment maintenance, and udder infusion. Antibiotic therapy has proven to be ineffective in controlling the disease. Proper sanitation, including pre- and postmilking teat dipping, good udder infusion techniques, and culling of carrier animals is essential in controlling this microorganism in a dairy herd. Data obtained during this study proves that several generic classes of teat dips are efficacious against the most common mycoplasmal mastitis species on teat skin.

\section{REFERENCES}

Boddie, R. L., S. C. Nickerson, and G. K. Kemp. 1994. Efficacy of two barrier teat dips containing chlorous acid germicides against experimental challenge with Staphylococcus aureus and Streptococcus agalactiae. J. Dairy Sci. 77:3192-3197.

Boddie, R. L., and S. C. Nickerson. 1996. Efficacy of teat dips containing a hypochlorous acid germicide against experimental challenge with Staphylococcus aureus and Streptococcus agalactiae. J. Dairy Sci. 79:1683-1688.

Bushnell, R. B. 1984. Mycoplasma mastitis. Vet. Clin. North Am. Large Anim. Pract. 6:301-312.

Gelinas, P., and J. Goulet. 1983. Neutralization of the activity of eight disinfectants by organic matter. J. Appl. Bacteriol. 54:243-247.

Jasper, D. E., J. D. Dellinger, and H. D. Hakanson. 1976. Effectiveness of certain teat dips and sanitizers in vitro and on teat skin against Mycoplasma agalactiae subsp. bovis. Cornell Vet. 66:164-171.

Laboratory Handbook on Bovine Mastitis. 1999. National Mastitis Council, Madison, WI.

Philpot, W. N., R. L. Boddie, and J. W. Pankey. 1978. Hygiene in the prevention of udder infections. IV. Evaluation of teat dips with excised cows' teats. J. Dairy Sci. 61:950-955. 